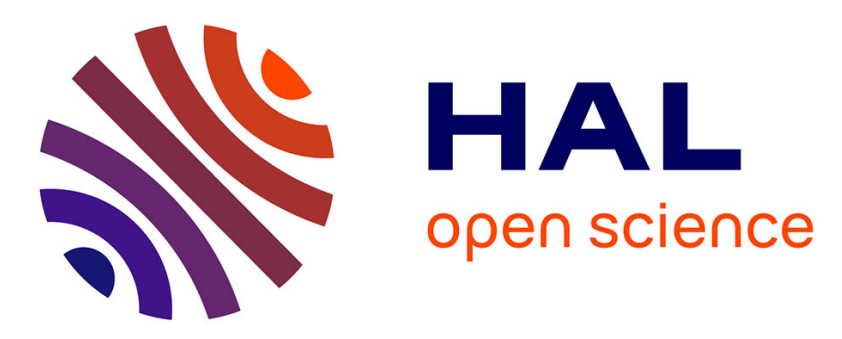

\title{
Toward setting public health guidelines for chemicals in indoor settled dust?
}

Philippe Glorennec, Derek G. Shendell, Pat E. Rasmussen, Roger Waeber, Peter Egeghy, Kenichi Azuma, Aurélie Pelfrêne, Barbara Le Bot, Williams Esteve, Guillaume Perouel, et al.

\section{To cite this version:}

Philippe Glorennec, Derek G. Shendell, Pat E. Rasmussen, Roger Waeber, Peter Egeghy, et al.. Toward setting public health guidelines for chemicals in indoor settled dust?. Indoor Air, 2021, 31 (1), pp.1_. 10.1111/ina.12722 . hal-02926293

\section{HAL Id: hal-02926293 https://hal.science/hal-02926293}

Submitted on 9 Sep 2020

HAL is a multi-disciplinary open access archive for the deposit and dissemination of scientific research documents, whether they are published or not. The documents may come from teaching and research institutions in France or abroad, or from public or private research centers.
L'archive ouverte pluridisciplinaire HAL, est destinée au dépôt et à la diffusion de documents scientifiques de niveau recherche, publiés ou non, émanant des établissements d'enseignement et de recherche français ou étrangers, des laboratoires publics ou privés. 


\section{INDOOR AIR}

\section{Towards setting public health guidelines for chemicals in indoor settled dust?}

\begin{tabular}{|r|l|}
\hline Journal: & Indoor Air \\
\hline Manuscript ID & INA-20-05-161 \\
\hline Manuscript Type: & Original Article \\
\hline Author: & $13-$ May-2020 \\
\hline Complete List of Authors: & $\begin{array}{l}\text { Glorennec, Philippe; EHESP-School of Public Health, France; IRSET, } \\
\text { Shendell, Derek; Rutgers School of Public Health, Department of } \\
\text { Environmental and Occupational Health; Rutgers School of Public Health, } \\
\text { NJ Safe Schools Program } \\
\text { Rasmussen, Pat; Health Canada, Environmental Health Science Research } \\
\text { Bureau; University of Ottawa, Earth and Environmental Sciences } \\
\text { Waeber, Roger; Swiss Federal Office of Public Health, Consumer } \\
\text { Protection Directorate } \\
\text { Egeghy, Peter; U.S. EPA, National Exposure Research Laboratory } \\
\text { Azuma, Kenichi; Kindai University Faculty of Medicine Hospital, } \\
\text { Department of Environmental Medicine and Behavioral Science } \\
\text { Pelfrêne, Aurélie; Yncrea Hautes-de-France Engineering Universities } \\
\text { Group, Laboratoire Génie Civil et géo-Environnement } \\
\text { Le Bot, Barbara; EHESP; IRSET, } \\
\text { Estève, Williams; Institut National de Recherche et de Sécurité, } \\
\text { Métrologie des Polluants } \\
\text { Perouel, Guillaume; Anses } \\
\text { Pernelet-Joly, Valérie; Anses } \\
\text { Noack, yves; Aix-Marseille-University; CEREGE } \\
\text { Delannoy, Matthieu; University of Lorraine } \\
\text { Keirsbulck, Marion; Anses } \\
\text { Mandin, Corinne; CSTB, Health and Comfort }\end{array}$ \\
\hline Keywords: & $\begin{array}{l}\text { Environmental health, exposure, indoor air quality, indoor environment, } \\
\text { chemical safety, environmental policy }\end{array}$ \\
\hline & \\
\hline & \\
\hline
\end{tabular}

\section{SCHOLARONE" Manuscripts}




\section{Towards setting public health guidelines for chemicals in indoor settled dust?}

Authors:

Glorennec P., Univ Rennes, EHESP, Inserm, Irset (Institut de recherche en santé, environnement et travail) - UMR_S 1085, Rennes, France

Shendell D.G., Department of Environmental \& Occupational Health, Rutgers School of Public Health Piscataway, NJ, U.S.A.; New Jersey Safe Schools Program, Rutgers School of Public Health, Piscataway, NJ, U.S.A.

Rasmussen P.E., Environmental Health Science and Research Bureau, Healthy Environments and Consumer Safety Branch, Health Canada, Ottawa, Canada

Waeber R., Consumer Protection Directorate, Federal Office of Public Health, Berne, Switzerland Egeghy P., Office of Research and Development, U.S. Environmental Protection Agency, Research Triangle Park, NC, USA

Azuma K., Department of Environmental Medicine and Behavioral Science, Kindai University Faculty of Medicine, Osakasayama, Japan

Pelfrêne A.,Yncréa Hauts-de-France, ULR 4515, Laboratoire Génie Civil et géo-Environnement (LGCgE), F-59000 Lille, France

Le Bot B., Univ Rennes, EHESP, Inserm, Irset (Institut de recherche en santé, environnement et travail) - UMR_S 1085, Rennes, France

Esteve W., Département Métrologie des Polluants, Institut National de Recherche et de Sécurité (INRS), Vandoeuvre-lès-Nancy, France

Perouel G., Agency for food, environmental and occupational health safety (Anses), France Pernelet Joly, V. Agency for food, environmental and occupational health safety (Anses), France Noack, Y., Aix-Marseille University, CNRS, IRD, INRAe, Collège de France, CEREGE, Aix-enProvence, France

Delannoy M., URAFPA, Université de Lorraine, INRAe, USC 340, 54500 Vandœuvre-lès-Nancy Keirsbulck, M., Agency for food, environmental and occupational health safety (Anses), France Mandin C. University of Paris-Est, Scientific and Technical Center for Building (CSTB), Health and Comfort Department, French Indoor Air Quality Observatory (OQAI), France. 
Authors express here their personal point of view, without institutional and/or agency endorsement.

\begin{abstract}
Indoor settled dust may result in substantial human exposure to chemicals, especially by ingestion following hand-to-mouth or hand-to-object-to-mouth contact. As with other environmental media related to exposure, dust may thus be subject to regulation. An international scientific workshop was convened in Paris in September 2019 to assess the relevance for public health of setting guidelines for indoor settled dust, and secondly to discuss scientific and technical challenges related to such guidelines. The main discussions and conclusions, with consensus achieved, are reported herein. Discussions concerned general considerations, objectives and definitions, relevance for a health-based guideline, units of measure, and finally derivation of the guideline. These points should be addressed when considering an indoor settled dust guideline as part of a policy to reduce exposure indoors to a given chemical or group of chemicals.
\end{abstract}

\title{
Practical Implications
}

Indoor settled dust may result in substantial human exposure to chemicals. An international scientific workshop was convened in Paris in September 2019 to assess the relevance for public health of setting guidelines for indoor settled dust, and to discuss related scientific and technical challenges. An indoor settled dust guideline can inform future policy to help reduce indoor exposure to chemicals.

\section{Keywords}

Environmental health, exposure, indoor air quality, indoor environment, chemical safety, environmental policy. 


\section{Introduction}

Indoor settled dust may result in direct human exposure to chemicals by ingestion following hand-tomouth or hand-to-object-to-mouth contact, inhalation of re-suspended particles, or dermal penetration by contact. This exposure can be evidenced by the existence of a correlation between the concentration of a compound in dust and its concentration (or concentration of a metabolite) in relevant human tissues or body fluids. For lead, the contribution of ingested settled dust to total exposure is well documented by numerous studies with consistent results. Lanphear et al. (1998) in the United States, Levallois et al. (2014) in Quebec, Canada, and Etchevers et al. (2015) in France have demonstrated a significant correlation between the lead concentration of sampled floor dust and the blood lead levels of children. A recent review of studies conducted since 2005 on chemicals in dust deposited in indoor environments in Europe, North America, Australia and New Zealand suggested dust by ingestion can be a relevant source of exposure for a variety of chemicals (Larsson and Berglund, 2018). In particular, the authors showed dust ingestion can be a strong contributor to total dust exposure for brominated flame retardants, certain phthalates and polycyclic aromatic hydrocarbons (PAHs).

Controlling environmental exposure is one of the ways to reduce potential damage to human health. Guidelines exist for outdoor air and indoor air, water, food, consumer products, building materials, and sometimes soils, but not for dust with the exception of lead: in 2019, U.S. EPA lowered the dustlead hazard standards for floors to $108 \mu \mathrm{g} / \mathrm{m}^{2}\left(10 \mu \mathrm{g} / \mathrm{ft}^{2}\right)$ to protect children from the harmful effects of lead exposure (USEPA 2019).

In France, the agency for food, environmental and occupational health safety (Anses) studies the feasibility and relevance of setting guidelines for chemicals present in indoor settled dust in dwellings and public places as schools, for instance. Anses proposed to discuss and address the associated challenges such as multi-pathway and multi-route exposure within the scientific community. Anses created a dedicated working group in 2018 and, in the absence of literature on indoor settled dust guidelines, a dedicated scientific international workshop was convened in September 2019 in Paris. The objectives were firstly to assess the relevance for public health of setting guidelines for indoor settled dust (Indoor Settled Dust Guideline, or ISDG), and secondly to discuss scientific and technical challenges related to such guidelines. The main discussions and conclusions, with consensus achieved, are reported.

\section{General considerations}

Before setting an ISDG, its public health benefit has to be evaluated. While this benefit may seem obvious for lead, the benefit would need to be assessed separately for other chemicals found in indoor settled dust.

The objective of an ISDG should not be to promote measurements of settled dust concentrations by individuals themselves.

Any guideline such as an ISDG should be accompanied by a measurement protocol, including both sampling and analytical aspects. 
Independently of a possible ISDG, a general public health risk communication message should be to clean and remove dust on surfaces, especially when accessible to children, as often as possible.

\section{Key points}

\section{Objectives and proposal for corresponding definitions}

A human health based guideline like an ISDG helps to answer the question "is there a risk?" It could be a "concern" or "alert" value, depending on the level of risk corresponding to the guideline. A "concern" ISDG may correspond to dose via ingested dust equal to or higher than a fraction of tolerable daily intake (e.g. $20 \%$ for non-carcinogenic endpoints), while an "alert" ISDG may correspond to an ingested dust equal to or higher than the tolerable daily intake.

Another complementary environment-based value may be useful to answer the question: "is there contamination?" Such a comparison value would be based on typical values of the environmental distribution, e.g. $9^{\text {th }}$ percentile of observed values in national or regional indoor settled dust surveys. This approach is oriented towards source reduction, different environments (schools, dwellings, etc.) have to be considered.

\section{Relevance criteria for a health based guideline}

An ISDG may be relevant for chronic environmental exposures in cases where dust accounts for a "certain part" of total exposure for the majority of the target population, or, for the most exposed people. Given the inherent uncertainty, the group thought this "certain part" must be substantial, perhaps situated around $30-50 \%$ of total exposure for the majority or the most exposed people. The discussion of relevance should therefore also consider the possible existence of other exposure sources (diet, consumer products...).

In addition, the relevance of an ISDG depends also on the availability of a toxicological reference value (oral chronic reference dose or tolerable daily intake for instance).

A priority ranking of target compounds is necessary, without excluding banned compounds because of their possible long persistence in the environment.

Cumulative risks need to be considered, e.g., phthalates instead of as diethyl hexyl phthalate, notably because of continuous substitution of an individual chemical or congener in a category.

\section{Measurement Units for ISDG}

Two expressions of measurement units, surface area concentration (or loading) and mass concentration (or concentration), both have their own strengths and limitations, and are thus complementary.

Loading $\left(\mu \mathrm{g} / \mathrm{m}^{2}\right)$ was judged by the group to be a better indicator of exposure because it combines the dustiness of the indoor environment and the concentration of the compound in dust (Rasmussen et al., 2017). Studies with lead have suggested dust loading correlates better with children's blood levels than does the concentration (Davies et al, 1990; Lanphear et al, 1995). Its measurement could be achieved with a wipe or with a specific vacuum cleaner (Mercier et al., 2011; Kubwabo et al., 2013; Rasmussen et al., 2017), on a measured surface area. One limitation is the spot measurement of loading is influenced by the delay between 
last cleaning and sampling. Another limitation is the assessment of calculated dose needs an empirically derived -transfer coefficient, expressed in $\mathrm{m}^{2} /$ day, to aggregate the mass transfer associated with a series of contacts. An alternative is to use a default dustiness assumption in $\mathrm{mg} / \mathrm{m}^{2}$ and a default dust intake rate in $\mathrm{mg} /$ day (or a conservative intake rate for a protective health-based value). Both transfer coefficient and default dustiness assumptions have large uncertainties (Cohen Hubal et al., 2006; Wilson et al., 2016).

Concentration $(\mu \mathrm{g} / \mathrm{g})$ more clearly identifies presence of sources, and is less influenced by the delay since the last cleaning. A strength is this value could be obtained from the analysis of dust easily collected in the bag of a vacuum cleaner (household or specific) (Kubwabo et al., 2013; Rasmussen et al., 2017). Estimates of intake and dose, however, still necessitate the use of a default, age-specific dust intake rate in mg/day (U.S. Environmental Protection Agency. Exposure Factors Handbook).

In addition, the selection of a sampling protocol (e.g. surface wipe versus vacuum) may be driven by the risk assessment approach to be used, but also by the need to collect adequate dust mass for analysis as well as to avoid inadvertent contamination of the dust sample.

\section{Deriving an ISDG}

Because both exposure and susceptibility (and vulnerability to adverse health outcomes) vary over the course of an individual's lifetime, different age groups have to be considered during the guideline derivation process, even if at the end a unique value, the lowest one, is proposed.

In the absence of complete data, use of an arbitrary proportional contribution of ingested dust to total exposure is recommended, because it is easier to calculate (less data needed), easier to communicate and allows consistency of the approach between media (e.g. drinking water guidelines). A default contribution of $20 \%$ such as is recommended in the WHO drinking water quality guidelines (World Health Organization 2011) or in the Canadian protocol for setting soil quality guidelines (Canadian Council of Ministers of the Environment, 2006) is suggested, which may be further modified if data make it possible and more useful. An alternative approach, but not recommended, is to determine contribution of ingested dust by allocating rates of intake from other pathways and routes of exposures to the toxicological reference value; however, this approach requires more data, especially recent representative data, and the confidence that every source of exposure has been identified.

Concerning the oral bioaccessibility of chemicals in dust, a default value of $100 \%$ is recommended, which could be replaced with a defensible lower value if robust data are available. Indeed, there are no in vivo validated tests for organics, and therefore few data, whereas there is a large variability between chemicals and among places (Raffy et al. 2018). Considering a pathway specific bioaccessibility adjustment would ideally require, to ensure consistency, also considering such a correction for other exposure pathways and routes, which may be difficult in practice due to lack of data. 


\section{Conclusion}

The workshop participants reached a consensus that an indoor settled dust guideline, or ISDG, may add value to and be an integral component in support of a general policy to reduce exposure to a given chemical or group of chemicals.

\section{Acknowledgements:}

Anses funded and organised this seminar that was prepared by an experts working group. The views expressed in this article are those of the authors and do not necessarily represent the views or the policies of the U.S. Environmental Protection Agency, or any other listed agency or institution.

Conflicts of interest:

The authors declare they do not have any financial conflict of interest associated with the question of setting of public health guidelines for indoor settled dust. 
References

Cohen Hubal, E.A., Egeghy, P.P., Leovic, K.W., \& Akland, G.G. (2006). Measuring potential dermal transfer of a pesticide to children in a child care center. Environmental Health Perspectives. 114(2), 264-9.

Davies, D.J.A., Thornton, I., Watt, J.M., Culbard, E.B., Harvey, P.G., Delves, H.T., Sherlock, J.C., Smart, G.A., Thomas, J.F.A., and Quinn, M.J. (1990). Lead intake and blood lead in two-year-old U.K. urban children. Science of the Total Environment, 90, 13-29.

Etchevers, A., Le Tertre, A., Lucas, J. P., Bretin, P., Oulhote, Y., Le Bot, B., \& Glorennec, P. (2015). Environmental determinants of different blood lead levels in children: A quantile analysis from a nationwide survey. Environment International, 74, 152-159.

Kubwabo C, Rasmussen PE, Fan X, Kosarac I, Wu F, Zidek A, Kuchta SK. Analysis of selected phthalates in Canadian indoor dust collected using household vacuum and standardized sampling techniques. Indoor Air. 2013;23:506-514.

Lanphear BP, Emond M, Jacobs DE, Weitzman M, Tanner M, Winter NL, Yakir B, Eberly S. (1995). A side-by-side comparison of dust collection methods for sampling lead-contaminated house dust. Environmental Research, 68(2), 114-23.

Lanphear, B. P., Matte, T. D., Rogers, J., Clickner, R. P., Dietz, B., Bornschein, R. L., ... \& Rabinowitz, M. (1998). The contribution of lead-contaminated house dust and residential soil to children's blood lead levels. A pooled analysis of 12 epidemiologic studies. Environmental Research-, 79, 51-68.

Larsson, K., \& Berglund, M. (2018). Children's exposure to chemicals in indoor environments-a literature survey of chemicals in dust. Karolinska institutet. Report 2018-06-15. $102 p$. http://www.diva-portal.org/smash/get/diva2:1220692/FULLTEXT01.pdf. Last accessed 2020 may 13.

Levallois, P., St-Laurent, J., Gauvin, D., Courteau, M., Prévost, M., Campagna, C., ... \& Rasmussen, P. E. (2014). The impact of drinking water, indoor dust and paint on blood lead levels of children aged 1-5 years in Montréal (Québec, Canada). Journal of Exposure Science \& Environmental Epidemiology, 24(2), 185-191.

Mercier, F., Glorennec, P., Thomas, O., \& Bot, B. L. (2011). Organic contamination of settled house dust, a review for exposure assessment purposes. Environmental Science \& Technology, 45(16), 67166727.

Raffy G, Mercier F, Glorennec P, Mandin C, Le Bot B. Oral bioaccessibility of semi-volatile organic compounds (svocs) in settled dust: A review of measurement methods, data and influencing factors. Journal of Hazardous Materials. 2018;352:215-227.

Rasmussen PE, Levesque C, Chenier M, Gardner HD. (2017) Rare earth elements and select actinoids in the Canadian House Dust Study. Indoor Air. 2017;27:965-976. 
U.S. Environmental Protection Agency. Exposure Factors Handbook. Retrieved from: https://www.epa.gov/expobox/about-exposure-factors-handbook (Last accessed May 1, 2020).

U.S. Environmental Protection Agency (USEPA). 2019. Review of the dust-lead hazard standards and the definition of lead-based paint. Fed Reg 84 FR 32632. https://www.federalregister.gov/documents/2019/07/09/2019-14024/review-of-the-dust-leadhazard-standards-and-the-definition-of-lead-based-paint (last accessed May 5, 2020)

World Health Organization (WHO). 2011. Guidelines for drinking-water quality- recommendations. Geneva:WHO. https://www.who.int/water sanitation health/publications/dwq-guidelines-4/en/ (last accessed May 5, 2020).

Wilson, R., Mitchell, I., \& Richardson, G. M. (2016). Estimation of dust ingestion rates in units of surface area per day using a mechanistic hand-to-mouth model. Human and Ecological Risk Assessment: An International Journal, 22(4), 874-881. 